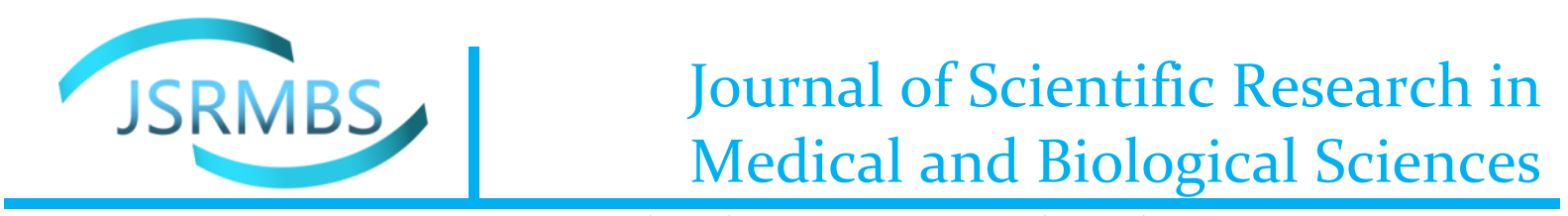

ISSN 2709-0159(print) and ISSN 2709-1511 (online)

\title{
THE ROLE OF DIAGNOSTIC LAPAROSCOPY IN THE UNEXPLAINED INFERTILITY CASES
}

\author{
Ibrahim Arafa I. Hamed ${ }^{1}\left(\mathbb{D}\right.$, Nahla Waer Shady ${ }^{1} \mathbb{D}$, Abdu Saeed Ait-Allah ${ }^{2} \mathbb{D}$ \\ ${ }^{1}$ Obstetrics and Gynecology Department, Aswan University hospital, Aswan, Egypt \\ ${ }^{2}$ Obstetrics and Gynecology Department, Sohag University Hospital, Aswan, Egypt
}

\section{ARTICLE INFO \\ Received: 04 September 2021 \\ Revised: 06 November 2021 \\ Accepted: 07 November 2021 \\ Keywords: \\ Unexplained Infertility, \\ Diagnostic Laparoscopy, Pelvic Endometriosis}

Corresponding Author:

Ibrahim Arafa I. Hamed

Email:

Dr_ibrahim.arafa@yahoo.com

Copyright (c) 2021 by author(s) and Journal of Scientific Research in Medical and Biological Sciences.

This work is licensed under the Creative Commons Attribution International License (CC BY 4.0). http://creativecommons.org/licenses/ by/4.0/
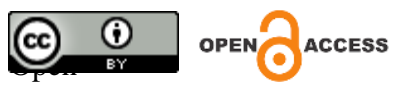

\begin{abstract}
Purpose: The study examines how useful laparoscopy is in finalizing the diagnosis of unexplained infertility.

Materials: The study included 50 women with 1 year or 2 years of infertility, who had a regular marital life with unprotected intercourse for more than a year, normal husband's semen analysis, normal ovulation by folliculometry, normal hormonal profile, and normal hysterosalpingogram at the department of Obstetrics and Gynecology at Aswan University Hospital from January to December 2019.

Methods: This is a cross-sectional observational study involving 50 women who underwent diagnostic laparoscopy after investigations and imaging failed to reveal the cause of infertility. During the procedure, the pelvis was inspected for any pathology, including the uterus, fallopian tubes, round ligaments, ureterovesical pouch, uterosacral ligaments, Douglas pouch, and ovarian fossae. Results: Diagnostic laparoscopy helped uncover abnormal pathologies such as endometriosis, adhesions, and tubal pathologies in 30 women $(60 \%)$ of the 50 included in the study, whereas no abnormality was detected in the remaining 20 (40\%).

Conclusion: Laparoscopy is not only a crucial diagnostic technique in infertility patients, but it can also help with treatment selections. Conducting laparoscopy in cases of unexplained infertility is linked to both peritubular adhesions and pelvic endometriosis. These pelvic disorders might not be appropriately detected or treated without laparoscopy, and hysterosalpingography and basic imaging such as pelvic ultrasonography are frequently ignored.
\end{abstract}

\section{INTRODUCTION}

Infertility is described as the inability to conceive after a year of regular unprotected sexual contact (Steril, 2008; Gurunath et al., 2011). This definition represents the prognosis approach to this condition, which is based on the fact that 84 percent of all women are predicted to conceive within one year of regular unprotected sexual intercourse in the general population. After two years, the percentage jumps to 92 percent, and after three years, it reaches 93 percent (te Velde et al., 2000).

Infertile couples whose conventional investigations, such as ovulation, tubal patency, and semen analysis, are normal are referred to as "unexplained infertility." Women under 35 years old had a prevalence of $21 \%$ and women over 35 years old had a prevalence of $26 \%$ when they visited a 
reproductive clinic (Maheshwari et al., 2008). Unexplained infertility refers to a couple's failure to conceive after 12 months of trying despite a complete evaluation, or after six months in women 35 and older (Steril, 2008).

Laparoscopic reproductive surgery plays a significant role in the diagnosis and treatment of infertility in the era of assisted reproductive techniques (ART). Although not all infertile women will require IVF, they will benefit from laparoscopy to aid natural conception, refer them to an IVF-ET approach, or improve IVF outcomes. It is self-evident that laparoscopy is not only a vital diagnostic technique, but it may also play a role in treatment decisions (Siam, 2014).

The added value of laparoscopy over a formal HSG is also determined by how much laparoscopy contributes to the treatment. The original treatment option may be revised to laparoscopic fertility-promoting surgery or a straight referral to an IVF facility, depending on the severity of the laparoscopic findings (Badawy et al., 2010).

Laparoscopy offers information on tubal and ovarian status, uterine normality, and is the gold standard for identifying numerous pelvic pathologies such as pelvic inflammatory disease, endometriosis, pelvic congestion, and TB (Sajida \& Majida, 2010).

The gold standard for identifying tubal pathology and other pelvic reproductive illnesses including adhesions and endometriosis is diagnostic laparoscopy. Once detected, surgical treatment can be administered to improve the chances of spontaneous conception. Moreover, in cases when the prognosis is poor, laparoscopy may be used to expedite the start of IVF by avoiding needless rounds of ovulatory stimulation with or without intrauterine insemination (IUI) (Moayeri et al., 2009).

\section{METHODOLOGY}

The study included 50 women with 1year or 2 years of infertility and who had a regular marital life with unprotected intercourse for more than a year, normal husband's semen analysis, normal ovulation by folliculometry, normal hormonal profile, and normal hysterosalpingogram at the department of Obstetrics and Gynecology at Aswan University Hospital from January to December 2019.

All of the study participants had diagnostic laparoscopy. The uterus, fallopian tubes, round ligaments, ureterovesical pouch, uterosacral ligaments, Douglas pouch, and ovarian fossae were all examined during the surgery. The size, form, and connection of both ovaries to the fimbrial end of the tubes were all evaluated. Detecting adhesions and determining their types (filmy, vascular, or cohesive), severity (as determined by the AFS classification), and locations(peritubular, periovarian, and omental). Endometriosis patches were discovered and categorized into four phases (I-minimal, II-mild, III-moderate, and IV-severe) based on the location, extent, and depth of endometriosis implants, the presence and severity of adhesions, and the existence and size of ovarian endometriomas (ASRM classification). The tubes were examined for any abnormalities in length and shape, as well as any pathology that could not be detected with HSG. The adhesions were graded using the following scale: Grade 0 (no adhesions), grade 1 (few adhesions, filmy thickness, avascularity), grade 2 (moderate thickness, limited vascularity), and grade 3 (severe, dense, vascularity) are the different levels of adhesions (Sages, 2008).

Patients in this study underwent pre-operative evaluations that included a clinical examination, basic investigations ( $\mathrm{CBC}$, coagulation profile, kidney functions, and liver functions), 
husband's semen analysis, hormonal profile (mid-luteal serum progesterone, serum prolactin, FSH, LH, TSH, and E2), and imaging (Folliculometry to follow up ovulation and Hysterosalpingography).

\section{RESULTS AND DISCUSSION}

The average age of the 50 people in the study was 28.65 .6 years. The bulk of them (73.7\%) are between the ages of 20 and 35. More than half of the participants in the study lived in rural areas. Nearly two-thirds (64\%) of the participants were obese. Infertility lasts an average of 4.21 .5 years, with a range of $2-10$ years. Table (1)

Table 1. Demographic Data

\begin{tabular}{|c|c|c|}
\hline Variable & No. $(n=50)$ & $\%$ \\
\hline Age: (years) & & \\
\hline Range & \multicolumn{2}{|c|}{$23-38$} \\
\hline$<20$ year & 0 & 0.0 \\
\hline 20 to $<35$ years & 37 & 73.7 \\
\hline$\geq 35$ year & 13 & 26.3 \\
\hline Mean \pm SD & \multicolumn{2}{|c|}{$28.6 \pm 5.6$} \\
\hline \multicolumn{3}{|l|}{ Residence: } \\
\hline Rural & 28 & 55.0 \\
\hline Urban & 22 & 45.0 \\
\hline \multicolumn{3}{|l|}{ Educational status: } \\
\hline Illtreated/ read \& write & 12 & 23.2 \\
\hline Basic education & 10 & 19.6 \\
\hline Secondary education & 20 & 40.2 \\
\hline University and above & 8 & 17.0 \\
\hline \multicolumn{3}{|l|}{ BMI (Kg/m2): } \\
\hline Normal & 18 & 36 \\
\hline Overweight & 32 & 64 \\
\hline Mean \pm SD (range) & \multicolumn{2}{|c|}{$24.1 \pm 4.4(23.6-29.8)$} \\
\hline \multicolumn{3}{|l|}{ Type of infertility: } \\
\hline Primary & 30 & 60.5 \\
\hline Secondary & 20 & 39.5 \\
\hline $\begin{array}{l}\text { Duration of infertility (years) } \\
\text { Mean } \pm \text { SD (range) }\end{array}$ & $4.2 \pm 1$ & \\
\hline
\end{tabular}

Table 2. Previous abortions were discovered in 5 of the instances.

\begin{tabular}{ccc}
\hline Mode of delivery in secondary type only & $(\mathrm{n}=20)$ & \\
\hline Vaginal delivery & 9 & 43.5 \\
Cesarean Section & 11 & 56.5 \\
Parity in secondary type only (n= 20) & & \\
Para 0 & 5 & 23.3 \\
Para 1 & 4 & 20.0 \\
Para 2-3 & 3 & 13.3 \\
More than 3 & 8 & 43.4 \\
Pervious abortion: & & \\
Yes & 5 & 24.8 \\
No & 15 & 75.2 \\
\hline
\end{tabular}

\section{Laparoscopic Findings among the Studied Sample}




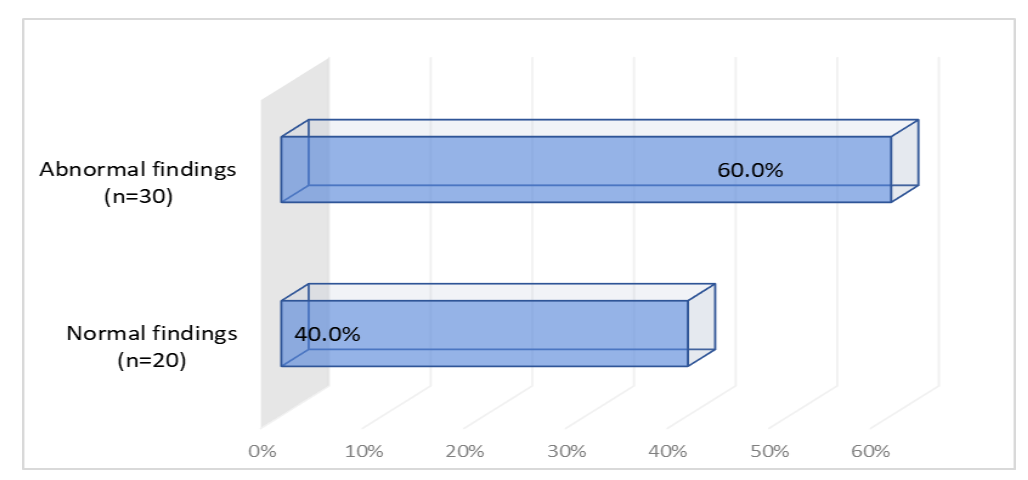

Figure 1. Reveals that Aberrant Findings were Found in $60 \%$ of the Cases Tested ( $N=30$ Instances)

Table (3) demonstrates that the presence of tubal lesions, followed by the presence of adhesions, was the most common aberrant finding.

Table 3. Abnormal Lap Finding

\begin{tabular}{ccc}
\hline Abnormal lap findings & $\mathbf{N}=$ & \% \\
\hline Adhesions & 8 & 26.7 \\
Endometriosis & 8 & 26.7 \\
Tubal lesions & 10 & 33.3 \\
Multiple lesions & 4 & 13.3 \\
\hline
\end{tabular}

Table (4) demonstrates that mild and moderate adhesions were the most common adhesion grades.

Table 4. Grades and sites of adhesions in the affected cases

\begin{tabular}{lccc}
\hline Site & Grade & N & \% \\
\hline All affected (n=9) & Mild & 4 & 44.4 \\
& Moderate & 4 & 44.4 \\
Fallopian tubes $(\mathbf{n}=\mathbf{2})$ & Severe & 1 & 11.2 \\
& Mild & 1 & 50.0 \\
Ovaries (n=2) & Moderate & 1 & 50.0 \\
& Mild & 1 & 50.0 \\
Douglas pouch $(\mathbf{n = 2 )})$ & Moderate & 1 & 50.0 \\
& Mild & 1 & 50.0 \\
Uterus $(\mathbf{n}=\mathbf{3})$ & Moderate & 1 & 50.0 \\
& Mild & 2 & 66.6 \\
\hline
\end{tabular}

Table (5) reveals that Stage I endometriosis was the most common.

Table 5. stages of endometriosis in the affected cases

\begin{tabular}{|c|c|c|c|}
\hline Sites & Grades & N & $\%$ \\
\hline \multirow{2}{*}{ All affected cases ( $\mathrm{n}=10)$} & Stage I & 6 & 60.0 \\
\cline { 2 - 4 } & Stage II & 4 & 40.0 \\
\hline
\end{tabular}

Table (6) demonstrates that the majority of tubal diseases are unilateral. Dilated congested tubes were the most common tubal pathology (63\%), followed by beaded unhealthy tubes (36\%).

Table 6. Tubal pathology in the affected cases

\begin{tabular}{llccc}
\hline \multicolumn{1}{c}{ Pathology } & \multicolumn{1}{c}{ Sites } & N & \% & \% of Total no.=11 \\
\hline Beaded unhealthy tubes & Unilateral & 2 & 50.0 & \\
$(\mathbf{n = 4})$ & Bilateral & 2 & 50.0 & 36.4 \\
$\begin{array}{l}\text { Dilated congested tubes } \\
(\mathbf{n}=7)\end{array}$ & Unilateral & -2 & 25.0 & \\
All affected & Bilateral & 5 & 75.0 & 63.6 \\
\hline
\end{tabular}




\section{Comparison between cases of primary and secondary infertility regarding abnormal} findings

In table (7), there were significant differences in the presence of findings, aberrant findings, endometriosis features, and adhesions characteristics between instances of primary and secondary infertility. In terms of adhesions and tubal disease, there is no substantial difference between cases of primary and secondary infertility.

Table 7. Cases of primary and secondary infertility regarding abnormal findings

\begin{tabular}{|c|c|c|c|c|c|}
\hline \multirow[t]{2}{*}{ Variable } & \multicolumn{2}{|c|}{$\begin{array}{c}\text { Primary } \\
(n=30)\end{array}$} & \multicolumn{2}{|c|}{$\begin{array}{c}\text { Secondary } \\
(n=20)\end{array}$} & \multirow[t]{2}{*}{ P-value } \\
\hline & No. & $\%$ & No. & $\%$ & \\
\hline Findings & & & & & 0.014 \\
\hline Normal & 15 & 50.0 & 5 & 25.0 & \\
\hline Abnormal & 15 & 50.0 & 15 & 75.0 & \\
\hline Abnormal findings $n=\mathbf{3 0}$ & & & & & $0.011 \#$ \\
\hline Endometriosis & 6 & 37.5 & 2 & 14.3 & \\
\hline Tubal & 6 & 37.5 & 4 & 28.6 & \\
\hline Adhesions & 2 & 12.5 & 6 & 42.8 & \\
\hline Multiple & 2 & 12.5 & 2 & 14.3 & \\
\hline $\begin{array}{l}\text { Tubal pathology characteristics } \\
\text { n= } 10 \text { cases tubal alone }+1 \\
\text { multiple }\end{array}$ & & & & & $0.050 \#$ \\
\hline Primary $(n=6)$ Secondary $(n=5)$ & & & & & \\
\hline Beaded unhealthy tubes & 2 & 33.3 & 2 & 40.0 & \\
\hline Dilated congested tubes & 4 & 66.6 & 3 & 60.0 & \\
\hline Site of tubal pathology & & & & & $0.0201 *$ \\
\hline Unilateral & 4 & 66.7 & 2 & 40.0 & \\
\hline Bilateral & 2 & 33.3 & 3 & 60.0 & \\
\hline Grade of endometriosis & & & & & 1. $000 \#$ \\
\hline Stage I & 3 & 50.0 & 2 & 50.0 & \\
\hline Stage II & 3 & 50.0 & 2 & 50.0 & \\
\hline
\end{tabular}

The relation between mode of delivery and abnormal findings in cases of secondary infertility

Table (9) demonstrates that in terms of findings, there was a substantial difference between the NVD and CS instances.

Table 9. Mode of delivery and abnormal findings in cases of secondary infertility

\begin{tabular}{|c|c|c|c|c|c|c|}
\hline \multirow{2}{*}{\multicolumn{2}{|c|}{ Variable }} & \multicolumn{2}{|c|}{$\begin{array}{l}\text { NVD } \\
(\mathrm{N}=9)\end{array}$} & \multicolumn{2}{|c|}{$\begin{array}{c}\mathrm{CS} \\
(\mathrm{N}=11)\end{array}$} & \multirow[t]{2}{*}{ P-value } \\
\hline & & No & $\%$ & No. & $\%$ & \\
\hline Findings & & & & & & $<0.001^{*}$ \\
\hline Normal & & 5 & 55.6 & 0 & 0.0 & \\
\hline Abnormal & & 4 & 44.4 & 11 & 100.0 & \\
\hline Abnormal Findings & & & & & & $<0.001 \#$ \\
\hline Adhesions only & & 1 & 25.0 & 8 & 72.7 & \\
\hline Endometriosis only & & 1 & 25.0 & 1 & 9.1 & \\
\hline Tubal only & & 1 & 25.0 & 1 & 9.1 & \\
\hline $\begin{array}{l}\text { Multiple } \\
\text { adhesions) }\end{array}$ & and & 1 & 25.0 & 1 & 9.1 & \\
\hline
\end{tabular}

Unexplained infertility is a diagnosis made in couples who have passed all of their conventional testing, such as ovulation detection, tubal patency, and sperm analysis. Laparoscopy is a typical method of detecting numerous pelvic pathologies and offers information about tubal and 
ovarian status, as well as uterine abnormalities. Grade 1 adhesions account for 4 cases (44.44\%), grade 2 adhesions for 4 cases (44.4\%), and grade 3 adhesions for 1 case (11.2 percent), whereas mild endometriosis accounts for 6 patients (60\%) and moderate endometriosis for 4 cases $(40 \%)$.

In terms of the study's effectiveness and success, laparoscopic findings in unexplained infertile women reveal pelvic pathology in 30 cases $(60 \%)$, whereas no pelvic pathology is discovered in 20 cases $(40 \%)$. Pelvic adhesions and endometriosis were discovered in $8(26.7 \%)$ of the patients, respectively, while tubal factor was found in 10 cases $(33.3 \%)$.

Another study (Drake et al. 1977) looked at 24 patients with unexplained infertility and discovered aberrant results in 18 of them (75\%). Unsuspected endometriosis was discovered in 11 of the 18 patients (46\%) and peritubular adhesions in 7 of them (29\%). They concluded that laparoscopy is a necessary last step in an otherwise negative infertility work-up.

In unexplained infertility cases, AL-Badawi et al., 1999 found that 136 (51\%) of women had normal laparoscopies, while 129 (49\%) had one or more aberrant laparoscopic findings. In 2012, Gocmen and Atak A total of 600 diagnostic laparoscopies were evaluated between 1995 and 2008. In $47.50 \%$ of initial infertile patients and $47 \%$ of secondary infertile instances, normal pelvic findings were discovered. Pelvic adhesions were the most common finding, occurring $20 \%$ of the time in the primary infertility group and $18 \%$ of the time in the secondary infertility group. The prevalence of endometriosis was found to be $15 \%$ in the primary infertility group and $11.5 \%$ in the secondary infertility group.

De Medeiros et al. (2012) reevaluated the role of laparoscopy in determining the treatment approach for infertility investigations. The study involved 237 patients who had been infertile for more than a year. All patients underwent a thorough assessment, with the male element being assessed by medical history and sperm tests. A normal pelvic cavity was found in $5.5 \%$ of laparoscopies, endometriosis in $76.4 \%$, pelvic adhesion in $17.2 \%$, ovarian adhesion in 24.8 $\%$, peritubular adhesion in $15.2 \%$, unilateral tubal occlusion in $5.5 \%$, and tubal sacculation, kinking, constriction, or fibrosis in $46.3 \%$

\section{CONCLUSION}

According to the findings of this study, the argument over whether or not to conduct laparoscopy in cases of unexplained infertility is linked to both peritubular adhesions and pelvic endometriosis. These pelvic disorders might not be appropriately detected or treated without laparoscopy, and hysterosalpingography and basic imaging such as pelvic ultrasonography are frequently ignored. As a result, diagnosing unexplained infertility without laparoscopy is not justified.

\section{ACKNOWLEDGMENTS}

I'd like to convey my heartfelt gratitude to all of my senior employees and colleagues at the Aswan University Hospital's Obstetrics and Gynecology department for their wonderful assistance during this project.

\section{REFERENCES}

Al-Badawi, I.A., Fluker, M.R. \& Bebbington, M.W. (1999). Diagnostic laparoscopy in infertile women with normal hysterosalpingograms. The Journal of reproductive medicine, (44),953-957. https://doi.org/10.14260/jemds/2020/202

Badawy, A., Khiary, M., Ragab, A., Hassan, M. \& Sherif, L. (2010). Laparoscopy-or not-for management of unexplained infertility. Journal of Obstetrics and Gynaecology, 30(7), 712-715. https://doi.org/10.3109/01443615.2010.508850 
De Medeiros, S.F.; Yamamoto, M.M.W.; Galera, B.B.; de Medeiros, M.A.S. \& Barbosa; J.S. (2012). Reassessment of the laparoscopy role in the investigation of infertility and treatment plan determination. Asian Pacific Journal of Reproduction, (1), 93-97. https://doi.org/10.1016/S2305-0500(13)60056-1

Drake, T., Tredway, D., Buchanan, G., Takaki, N. \& Daane, T. (1977). Unexplained infertility. A reappraisal Obstetrics and Gynecology, (50), 644-646.

Gurunath, S., Pandian, Z. \& Anderson, R.A. \& Bhattacharya, S. (2011). Defining infertility: a systematic review of prevalence studies. Human Reproduction Update, (17), 575-588. https://doi.org/10.1093/humupd/dmr015

Maheshwari, A., Hamilton, M. \& Bhattacharya, S. (2008). Effect of female age on the diagnostic categories of infertility. Human Reproduction, (23), 538-542. https://doi.org/10.1093/humrep/dem431

Moayeri, S.E., Lee, H.C., Lathi, R.B., Westphal, L.M., Milki, A.A., Garber, A.M. (2009). Laparoscopy in women with unexplained infertility: a cost-effectiveness analysis. Fertility and Sterility, (92), 471-80. https://doi.org/10.1016/j.fertnstert.2008.05.074

Sajida \& Majida, K. (2010). Role of combined diagnostic laparoscopy and simultaneous diagnostic hysteroscopy for evaluation of female subfertility factors. Journal of Surgery Pakistan, (15), 44-47. https://doi.org/10.18203/2320-1770.ijrcog20185437

Siam, S. (2014). Gynecologic laparoscopy and reproductive failure: Review of 4103 infertile Egyptian women. Middle East Fertility Society Journal, (19), 102-106. https://doi.org/10.1016/j.mefs.2013.05.011

Practice Committee of American Society for Reproductive Medicine. (2008). Definitions of infertility and recurrent pregnancy loss. Fertil Steril, 99(1), 63. https://doi.org/10.1016/j.fertnstert.2012.09.023 